Case Report

\title{
Nonimmunoglobulin Crystal-Storing Histiocytosis (CSH): Case Report and Literature Review
}

\author{
Manuel Beltran, ${ }^{1}$ Sharad Khurana, ${ }^{2}$ Yennifer Gil, ${ }^{3}$ Jason T. Lewis, ${ }^{4}$ Rohit Kumar, \\ and James M. Foran $\mathbb{D}^{6}$ \\ ${ }^{1}$ Division of General Internal Medicine, Mayo Clinic, Jacksonville, FL, USA \\ ${ }^{2}$ Division of Hematology \& Oncology, University of Arizona Cancer Center, Tucson, AZ, USA \\ ${ }^{3}$ Department of Anesthesia and Preoperative Medicine, Mayo Clinic, Jacksonville, FL, USA \\ ${ }^{4}$ Department of Pathology, Mayo Clinic, Jacksonville, FL, USA \\ ${ }^{5}$ Division of Medical Oncology and Hematology, University of Louisville, Louisville, KY, USA \\ ${ }^{6}$ Department of Hematology \& Oncology, Mayo Clinic, Jacksonville, FL, USA
}

Correspondence should be addressed to James M. Foran; foran.james@mayo.edu

Received 1 June 2020; Revised 17 September 2020; Accepted 5 October 2020; Published 20 October 2020

Academic Editor: Masayuki Nagasawa

Copyright (c) 2020 Manuel Beltran et al. This is an open access article distributed under the Creative Commons Attribution License, which permits unrestricted use, distribution, and reproduction in any medium, provided the original work is properly cited.

\begin{abstract}
Crystal-storing histiocytosis (CSH) is an uncommon condition in which histiocytes accumulate a crystalline matter within their cytoplasm. Generally, those crystals are composed of either monoclonal or polyclonal immunoglobulin chains, which have a strong association with an underlying lymphoproliferative or plasma cell disorder (LP-PCD). Rarely, CSH has been reported as local or generalized manifestation of a variety of benign disorders. These cases are associated with crystals composed of nonimmunoglobulin substances. We are reporting an exceptional case of a local colonic CSH with Charcot-Leyden crystals. This patient underwent a screening colonoscopy that detected some polyps. The biopsy reported tubular adenomas, with a markedly dense, transmural inflammatory infiltrates, which were predominantly composed of eosinophils and crystal-storing histiocytes containing Charcot-Leyden crystals. The patient had a negative workup for LP-PCD and autoimmune conditions, including a normal skeletal survey and bone marrow aspirate/biopsy. The only positive laboratory workup was an elevated absolute eosinophil count and a positive IgG anti-Strongyloides antibody. Giving those findings, this parasitic infection is the most likely etiology of the $\mathrm{CSH}$ in our patient. Although there was an initial negative evaluation for LP-PCD, close monitoring of patients with either immunoglobulin or nonimmunoglobulin CSH is recommended.
\end{abstract}

\section{Introduction}

Crystal-storing histiocytosis (CSH) is a unique entity presenting as sheets of histiocytes with accumulation of crystalline matter within the cytoplasm. It can present as either a localized or generalized disease and has a variable outcome depending on the underlying CSH etiology [1]. Most often, the crystals are composed of monoclonal or polyclonal immunoglobulin light or heavy chains and have a strong association with an underlying lymphoproliferative or plasma cell disorder (LP-PCD) [1-3]. Rarely, the crystals are composed of nonimmunoglobulin substances such as clofazimine, cystine, silica, or Charcot-Leyden crystals and are often seen in association with a variety of benign disorders [1]. Literature on nonimmunoglobulin CSH is scarce. We discuss here a case of presentation with a colonic-only nonimmunoglobulin CSH with Charcot-Leyden crystals, along with a review of literature on this rare disease.

\section{Case Description}

A 55-year-old man with a history of hypertension, hyperlipidemia, gout, recurrent $H$. pylori gastritis, gastroesophageal reflux with reflux esophagitis and esophageal stricture 
underwent a screening colonoscopy which showed polyps along with white nodular submucosa in the proximal ascending colon. Biopsy confirmed tubular adenomas, with a markedly dense, transmural inflammatory infiltrates predominantly composed of eosinophils and crystal-storing histiocytes containing Charcot-Leyden crystals (Figures 1 and 2). Besides the recurrent dyspeptic symptoms and dysphagia, he denied any other gastrointestinal symptoms such as cramping, diarrhea, or constipation. Review of system was negative for any fatigue, recurrent infections, bony pain, or easy bleeding/bruising. Laboratory workup showed an elevated absolute eosinophil count of 500 cells/ $\mu 1$ and a positive IgG anti-Strongyloides antibody. Serum evaluation for a monoclonal protein, serum free light chains, lactate dehydrogenase (LDH), and beta-2 microglobulin was normal. Tryptase levels and CHIC2, PDGFRA, and FIP1L1 gene regions were normal as well. A negative autoimmune workup was noted. Skeletal survey showed no lytic or blastic bony lesions, and CT scan of the chest, abdomen, and pelvis showed no lymphadenopathy or hepatosplenomegaly. Bone marrow aspirate/biopsy did not show any evidence of an underlying plasma cell disorder or any mast cell disorder. The patient was treated with ivermectin for Strongyloides stercoralis infection and continued to follow-up with gastroenterology for his antibiotic and pantoprazole-treated H. pylori gastritis and esophagitis. He continued to follow closely with hematology for monitoring of development of any LP-PCD in future.

\section{Discussion}

Around $90 \%$ cases of crystal-storing histiocytosis (CSH) are associated with an underlying LP-PCD such as multiple myeloma (MM), lymphoplasmacytic lymphoma (LPL), and monoclonal gammopathy of undetermined significance (MGUS) [1,2]. Overproduction of kappa light chain protein, abnormalities in specific stored paraprotein sequences, and resistance to intralysosomal degradation have been proposed as possible mechanisms of accumulation and crystallization of immunoglobulins in the cytoplasm of histiocytes $[3,4]$.

Approximately $8.8 \%$ of $\mathrm{CSH}$ cases are seen in association with a variety of benign disorders. Conditions with hyperactivated immune system such as rheumatoid arthritis, Fanconi syndrome, Crohn's disease, eosinophilic colitis, and mastocytosis; infections like H. pylori; and drugs like clozafamine have been reported in patients with CSH without an underlying LP-PCD $[2,3]$. In these cases, materials different from immunoglobulins have been described, including clofazimine-induced CSH, Charcot-Leyden crystalassociated $\mathrm{CSH}$, and $\mathrm{CSH}$ associated with hereditary cystinosis [2] (Table 1).

Besides the composition of the crystals, $\mathrm{CSH}$ can be classified as localized CSH (L-CSH), involving only one organ or site such as lung, pleura, stomach, kidney, bone marrow, thyroid, thymus, and parotid gland $[3,4]$, and generalized CSH (G-CSH), involving two or more distant organs or sites. [3]. According to Dogan et al., only $8 \%$ of localized $\mathrm{CSH}$ cases have been detected in the

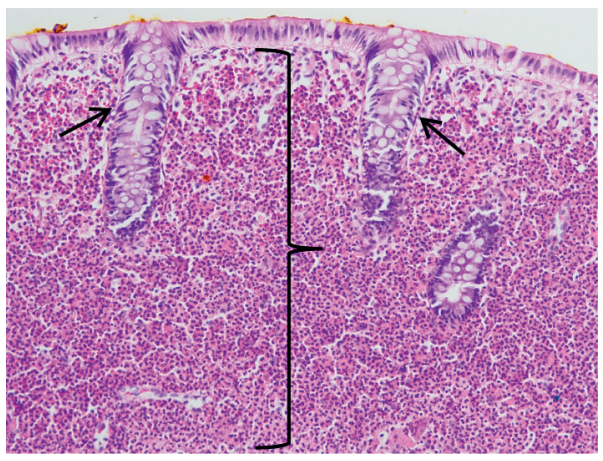

Figure 1: Medium power H\&E of the colonic mucosa demonstrating a diffuse expansion of the lamina propria by eosinophils (denoted by black bracket). There is displacement of the colonic crypts (black arrows). No other inflammatory cell types are seen.

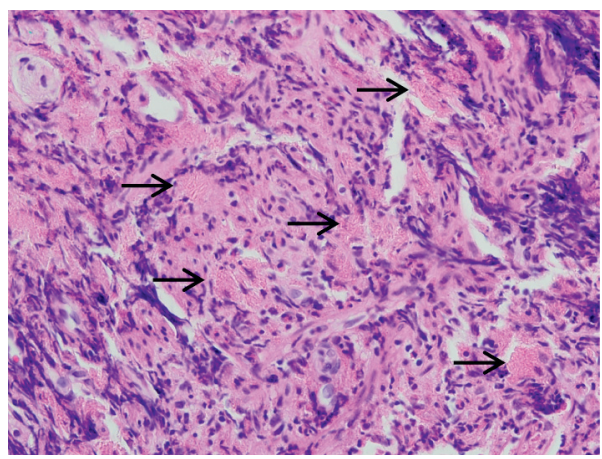

FIgURE 2: High power H\&E showing aggregates of histiocytes within the muscularis mucosa and superficial submucosa. The cytoplasm of the histiocytes contains eosinophilic Charcot-Leyden crystals which are present in the form of fine, granular, and needleshaped deposits within the macrophage cytoplasm (black arrows).

gastrointestinal tract. In fact, just 3 cases of colonic CSH have been described in the literature so far $[3,8]$, seen in association with eosinophilic colitis, MGUS, and lymphoma. We present here, colonic-only Charcot-Leyden crystals (CLC) CSH, possibly related to the patient's history of strongyloidiasis with associated peripheral eosinophilia.

Charcot-Leyden crystals have hexagonal and bipyramidal forms [11]. They are compounds of galectin-10 (Gal10), a member of the family of S-type lectin proteins [12]. Gal-10 is a major constituent of eosinophils, estimated to be around $7-10 \%$ of total cellular proteins. A higher percentage is usually a sign of eosinophilic inflammation [12]. This protein is insoluble at neutral $\mathrm{pH}$, remarkably resistant to various enzymes, and exhibits a tendency to form noncovalent aggregates [12]. Activated eosinophils trigger a nonapoptotic extracellular trap cell death called ETosis, where Gal-10 is homogeneously redistributed in the cytoplasm, followed by intracellular CLC formation. Subsequently, the eosinophil plasma membrane ruptures, releasing chromatin and vesicles together with CLC [12]. Additionally, pathogens and parasites may also induce eosinophilic apoptosis triggering a massive eosinophilic release of Gal-10, thereby resulting in extracellular CLC formation 
TABLE 1: Nonimmunoglobulin CSH reported in literature.

\begin{tabular}{|c|c|c|c|c|c|c|}
\hline Source & Sex/age & Patient history/underlying disease & $\begin{array}{c}\text { Organ }(s) \\
\text { involved by } \\
\text { CSH }\end{array}$ & Type of crystal & $\begin{array}{c}\text { Symptoms/ } \\
\text { indication for } \\
\text { workup }\end{array}$ & $\begin{array}{c}\text { Disease status } \\
\text { at last follow- } \\
\text { up }\end{array}$ \\
\hline $\begin{array}{l}\text { Sukpanichnant } \\
\text { [5] }\end{array}$ & $\mathrm{M} / 32 \mathrm{y}$ & Leprosy & SI and LN & $\begin{array}{l}\text { Clofazimine } \\
\text { crystals }\end{array}$ & $\begin{array}{c}\text { Chronic } \\
\text { abdominal pain }\end{array}$ & $\begin{array}{l}\text { Died } 2 \text { months } \\
\text { after diagnosis; } \\
\text { had an acute } \\
\text { onset of } \\
\text { dyspnea }\end{array}$ \\
\hline Gebrail [6] & $\mathrm{M} / 23 \mathrm{y}$ & Hereditary cystinosis & $\begin{array}{c}\text { Cornea, } \\
\text { conjunctiva, } \\
\text { BM }\end{array}$ & Cystine crystals & Pancytopenia & Not described \\
\hline Pais [7] & $\mathrm{F} / 44 \mathrm{y}$ & Leprosy & $\begin{array}{c}\text { Intra- } \\
\text { abdominal LN, } \\
\text { omentum, and } \\
\text { peritoneum }\end{array}$ & $\begin{array}{l}\text { Clofazimine } \\
\text { crystals }\end{array}$ & $\begin{array}{l}\text { Mild abdominal } \\
\text { pain }\end{array}$ & $\begin{array}{l}\text { Complete } \\
\text { remission }\end{array}$ \\
\hline Lewis [8] & $\mathrm{F} / 78 \mathrm{y}$ & Eosinophilic colitis & Colon & $\begin{array}{l}\text { Charcot-Leyden } \\
\text { crystals }\end{array}$ & $\begin{array}{c}\text { Chronic } \\
\text { abdominal pain } \\
\text { and diarrhea }\end{array}$ & Not described \\
\hline Singh [9] & $\mathrm{M} / 19 \mathrm{y}$ & Leprosy & $\begin{array}{l}\text { Duodenum and } \\
\text { jejunum }\end{array}$ & $\begin{array}{l}\text { Clofazimine } \\
\text { crystals }\end{array}$ & $\begin{array}{l}\text { Acute abdominal } \\
\text { pain }\end{array}$ & $\begin{array}{l}\text { Complete } \\
\text { remission }\end{array}$ \\
\hline Szeto [10] & $\mathrm{F} / 68 \mathrm{y}$ & $\begin{array}{l}\text { Disseminated } M . \text { abscessus, } \\
\text { clofazimine enteropathy }\end{array}$ & Terminal ileum & $\begin{array}{l}\text { Clofazimine } \\
\text { crystals }\end{array}$ & $\begin{array}{l}\text { Abdominal pain, } \\
\text { diarrhea, weight } \\
\text { loss, and } \\
\text { hematochezia }\end{array}$ & $\begin{array}{l}\text { Complete } \\
\text { remission }\end{array}$ \\
\hline Present case & $\mathrm{M} / 55 \mathrm{y}$ & Strongyloidiasis & $\begin{array}{c}\text { Proximal } \\
\text { ascending colon }\end{array}$ & $\begin{array}{c}\text { Charcot-Leyden } \\
\text { crystals }\end{array}$ & Epigastric pain & - \\
\hline
\end{tabular}

F, female; M, male; $y$, years; SI, small intestine; BM, bone marrow; LN, lymph nodes.

$[11,12]$. It has been demonstrated both in vitro and in vivo that macrophages/histiocytes are able to engulf CLC and Gal-10 to form additional CLCs in the phagosomes of macrophages, leading to CLC CSH $[11,12]$.

Strongyloidiasis is a disease caused by a nematode Strongyloides stercoralis. Clinical manifestations can range from asymptomatic eosinophilia to gastrointestinal symptoms, such as upper abdominal pain, diarrhea, anorexia, nausea, and vomiting. In addition, patients can develop cutaneous or pulmonary symptoms [13]. Strongyloides causes direct eosinophilic infiltrate in the colonic mucosa [14], and as a result, CLC deposits could be expected even in the absence of colorectal symptoms, as was seen in our patient. H. pylori have been described as a cause of CSH in the stomach [15]. Therefore, it could potentially be a differential etiology for our patients with colonic CSH. However, the colonic location of $\mathrm{CSH}$, the presence of eosinophilic infiltrate in the colonic polyp biopsy, peripheral eosinophilia, and the positive IgG anti-Strongyloides antibody make $H$. pylori an unlikely etiology of our patients with $\mathrm{CSH}$ [14].

$\mathrm{CSH}$ has been reported as a first manifestation or a subclinical stage of underlying neoplasms such as thymic lymphoma, multiple myeloma, or lymphoreticular malignancy $[1,15]$. As such, an initial negative evaluation for an LP-PCD does not obviate the need for a close follow-up in patients diagnosed with either immunoglobulin or nonimmunoglobulin CSH.

In conclusion, $\mathrm{CSH}$ is an uncommon phenomenon of aggregation of crystals within the histiocytic cytoplasm, which are usually made up of immunoglobulins. Nonimmunoglobulin $\mathrm{CSH}$ is extremely rare and is usually associated with benign conditions. We report here a Charcot-Leyden colonic-only $\mathrm{CSH}$ associated with Strongyloides infection in the absence of LP-PCD.

\section{Disclosure}

Manuel Beltran and Sharad Khurana are co-first authors.

\section{Conflicts of Interest}

The authors do not have any relevant conflicts of interest to report for this work.

\section{Authors' Contributions}

Manuel Beltran and Sharad Khurana contributed equally to this work.

\section{References}

[1] M. Joo, J. E. Kwak, S. H. Chang et al., "Localized gastric crystal-storing histiocytosis," Histopathology, vol. 51, no. 1, pp. 116-118, 2007.

[2] S. Dogan, L. Barnes, and W. P. Cruz-Vetrano, "Crystal-storing histiocytosis: Report of a case, review of the literature (80 cases) and a proposed classification," Head and Neck Pathology, vol. 6, no. 1, pp. 111-120, 2012.

[3] R. Kanagal-Shamanna, Z. Y. Xu-Monette, R. N. Miranda et al., "Crystal-storing histiocytosis: A clinicopathological study of 13 cases,” Histopathology, vol. 68, no. 4, pp. 482-491, 2016. 
[4] Y. Fujita, H. Oikawa, Y. Toya et al., "Gastric crystal-storing histiocytosis without any underlying disorders: report of a case," Human Pathology: Case Reports, vol. 14, pp. 73-77, 2018.

[5] S. Sukpanichnant, N. S. Hargrove, U. Kachintorn et al., "Clofazimine-induced crystal-storing histiocytosis producing chronic abdominal pain in a leprosy patient," The American Journal of Surgical Pathology, vol. 24, no. 1, pp. 129-135, 2000.

[6] F. Gebrail, M. Knapp, G. Perrotta, and H. Cualing, "Crystalline histiocytosis in hereditary cystinosis," Archives of $\mathrm{Pa}$ thology \& Laboratory Medicine, vol. 126, no. 9, 1135 pages, 2002.

[7] A. V. Pais, S. Pereira, I. Garg, J. Stephen, M. Antony, and Y. K. Inchara, "Intra-abdominal, crystal-storing histiocytosis due to clofazimine in a patient with lepromatous leprosy and concurrent carcinoma of the colon," Leprosy Review, vol. 75, no. 2, pp. 171-176, 2004.

[8] J. T. Lewis, J. N. Candelora, R. B. Hogan, F. R. Briggs, and S. C. Abraham, "Crystal-storing histiocytosis due to massive accumulation of Charcot-Leyden crystals: A unique association producing colonic polyposis in a 78-year-old woman with eosinophilic colitis," The American Journal of Surgical Pathology, vol. 31, no. 3, pp. 481-485, 2007.

[9] H. Singh, K. Azad, and K. Kaur, "Clofazimine-induced enteropathy in a patient of leprosy," Indian Jounal of Pharmacology, vol. 45, no. 2, pp. 197-198, 2013.

[10] W. Szeto, M. T. Garcia-Buitrago, L. Abbo, J. D. Rosenblatt, B. Moshiree, and M. I. Morris, "Clofazimine enteropathy: A rare and underrecognized complication of mycobacterial therapy," Open Forum Infectious Diseases, vol. 3, no. 3, pp. 1-4, 2016.

[11] J. Su, "A brief history of charcot-leyden crystal protein/ galectin-10 research," Molecules, vol. 23, no. 11, p. 2931, 2018.

[12] S. Ueki, Y. Miyabe, Y. Yohei et al., "Charcot-leyden crystals in eosinophilic Inflammation: active cytolysis leads to crystal formation," Current Allergy and Asthma Reports, vol. 19, no. 8, 2019.

[13] M. Montes, C. Sawhney, and N. Barros, "Strongyloides stercoralis: there but not seen," Current Opinion in Infectious Diseases, vol. 23, no. 5, pp. 500-504, 2010.

[14] A. A. Alfadda, M. A. Storr, and E. A. Shaffer, "Eosinophilic colitis: Epidemiology, clinical features, and current management," Therapeutic Advances in Gastroenterology, vol. 4, no. 5, pp. 301-309, 2011.

[15] M. Joo, "Rare gastric lesions Associated with helicobacter pylori infection: A histopathological review," Journal of $\mathrm{Pa}$ thology and Translational Medicine, vol. 51, no. 4, pp. 341-351, 2017. 